J. Perimal. Mod. $13(1085) 87$

\section{Evaluation of a one-year Swedish neonatal care population}

\author{
P. Hoolmquist, N. W. Svenningeren
}

Neonatal Care Unit, Department of Pediatricy, Universily Hostpital, Lund, Sweden

\section{Introduction}

During the late 1970's studies have recorded a progressive fall in perinatal mortality with no or just a slight increase in the incidence of cerebral palsy $[4,8]$ whereas others have been more pessimistic about the outcome for infants in nead of noonatal care [27]. Still uncertainties exist whether handicans in such infants are mainly of perinatal origin or not $[4,8]$. The introduction of new modes of therapy in neonatal care has improved the mortality rate especially in low birthweight infants but also introduced new risks for the growing number of survivors $[3,5,23]$. Thus the role of neonatal care as one indispensable institution in any programme for the prevention of handicaps is still a matter of controversy.

The aim of this investigation was to present the panorama of a one-year regional population treated in a Swedish neonatal unit and of the total perinatal mortality in the southern region of Sweden. The postnatal mortality rate, the major neonatal diseases and later handicaps until 3 years of age were recorded in order to estimate the effectiveness of neonatal care programmes for the future regional planning and organization.

\section{Material and methods}

Prom January $1 \mathrm{st}$ through December 31 st, 1977, 527 infants from the southern part of Sweden
(2112727 inhabitants) wore arlmitted tos the neonatal unit of the University Hospital in Lund. For neonatal care there are 2 wards: an intensive carce unit with 14 beds, and an intermediate care unit wilh 10 beds. Outborn infants were admilted for neonatal care mainly because of respiratory and other adaptalion problems owing to e. g. severe astphyxia, hyaline membrane disease, immalurily (less than 32 wecks of gestation) or severe congenital malformations.

Infants requiring a period of reconvalesecence after treatment in the nconatal unit and infants with uncomplicated hyperbilirubinaemia, feeding difficulties or minor problems requiring supervision or examination were cared for in the intermediate care unit. This unit is situated in the Maternity Hospital and the mothers can stay there with their babies. The neonatal care principles have been published previously [15]. During the year studied routine scanning with ultrasonography for intracranial hemorrhage of the newhorn was not yet availahle. Parents were allowed and encouraged to visit their bahies at any time both in the neonatal to visit their bahies al any lime both in the neonalal unit and the intermediate care ward.

Data on inborn and outborn infants regarding. adaptation problems, respiratory function and duration of treatment were analyzed. Diagnositic criteria for respiratory problems have been made aceording to a recent collaboralive 
Swedish study [9]. All infants were followed with neurodevelopmental re-examinations in our special care follow-up clinics until 2 to 4 years of age.

Data on differentiated costs of neonatal care and care of handicapped children were obtained form the hospital administration department for health care economy and statistics and the regional child habilitation center, respectively. The amounts are expressed in the 1977 currency in Swedish crowns (Sw. Cr.) and US dollars (US \$).

\section{Results}

\subsection{Mortality and survival rates}

In 1977 there were 3176 deliveries in the Maternity Hospital in Lund. Liveborn infants were 3164 and 435 of these inborns were transferred to the neonatal unit. Hospitals in the region with 14140 births this year admitted 92 infants (outborns). The perinatal mortality rate varies between $0.31-1.83 \%$ with an average of $0.97 \%$ for the referral clinics and $0.69 \%$ for the hospital in Lund. The low birthweight (LBW) rate for the total region was $3.8 \%$ and for the inborns slightly higher $(4.5 \%)$ than for the outborns (3.5\%) (Tab. I).

From 1977 through 1981, 24 inborn children died postnatally (Tab. II). Five died within minutes after birth and were not transferred to the neonatal unit. In the total inborn population another 7 infants died after 6 months of age. After 6 months of age no inborn infant treated in the neonatal unit died. Among outborn infants 3 died after 6 months of age.

For those who died after 1 month of age the causes of death were 4 congenital malformations, 1 sever asphyxia and 1 sudden infant death syndrome (SIDS). In the total inborn population there were 3 SIDS but non belonged to the neonatal unit treated population.

Tab. I. Perinatal statistics

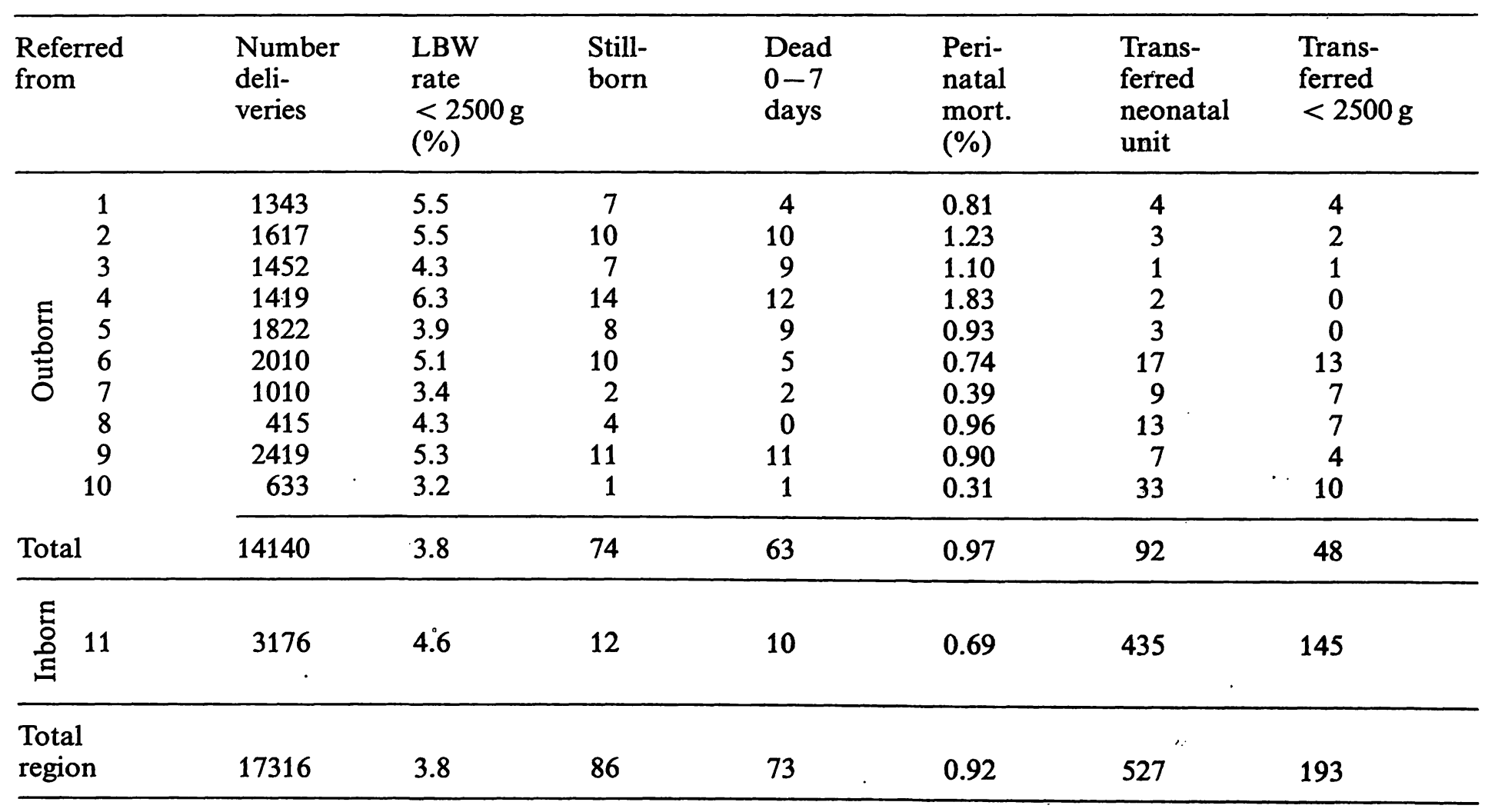


Tab. II. Total mortality for inborn and outborn infants

\begin{tabular}{lllc}
\hline & \multicolumn{2}{l}{ Neonatal unit transfers } & $\begin{array}{l}\text { Total inborn } \\
\text { population 1977 }\end{array}$ \\
\cline { 2 - 4 } & Inborn & Outborn & 3176 \\
\hline Number & 435 & 92 & 12 \\
Stillborn & - & - & $10^{*}$ \\
\hline Dead 0-1 w & 5 & 6 & 3 \\
Dead 1-4 w & 3 & 3 & 4 \\
Dead 4 w-6 m & 1 & 4 & 7 \\
Dead > 6 m & - & 2 & 24 \\
\hline Total & 9 & 15 & $0.75 \%$ \\
\hline Mortality rate & $2.07 \%$ & $15.20 \%$ & \\
\hline
\end{tabular}

* 5 infants died within minutes at the delivery ward.

\subsection{Panorama of neonatal care}

In 1977, $92(17.5 \%)$ of 527 infants in the neonatal unit were outborns. As shown in Tab. I, 46 of these were transferred from regional hospitals without pediatric wards (hospitals 8 and 10). Thus 92 minus $46=46(0.33 \%)$ of the total outborn population were infants in need of specialized neonatal care in the regional center. The corresponding figure for the total inborn population was $33(1.04 \%)$. The number of patients in the neonatal unit varied irregularly over the months but the proportion of inborns and outborns was unchanged.

The birthweight distribution and survival rate of all infants treated in the neonatal unit are shown in Fig. 1. The number of infants weighing $\leq 2500 \mathrm{~g}$ were 145 of 3164 liveborn inborns $(4.6 \%)$ and $539(48+491)$ of 14140 outborns $(3.8 \%)$ (Tab. I). The survival rates in the inborn birthweight groups were: below $1000 \mathrm{~g} 57 \%$,

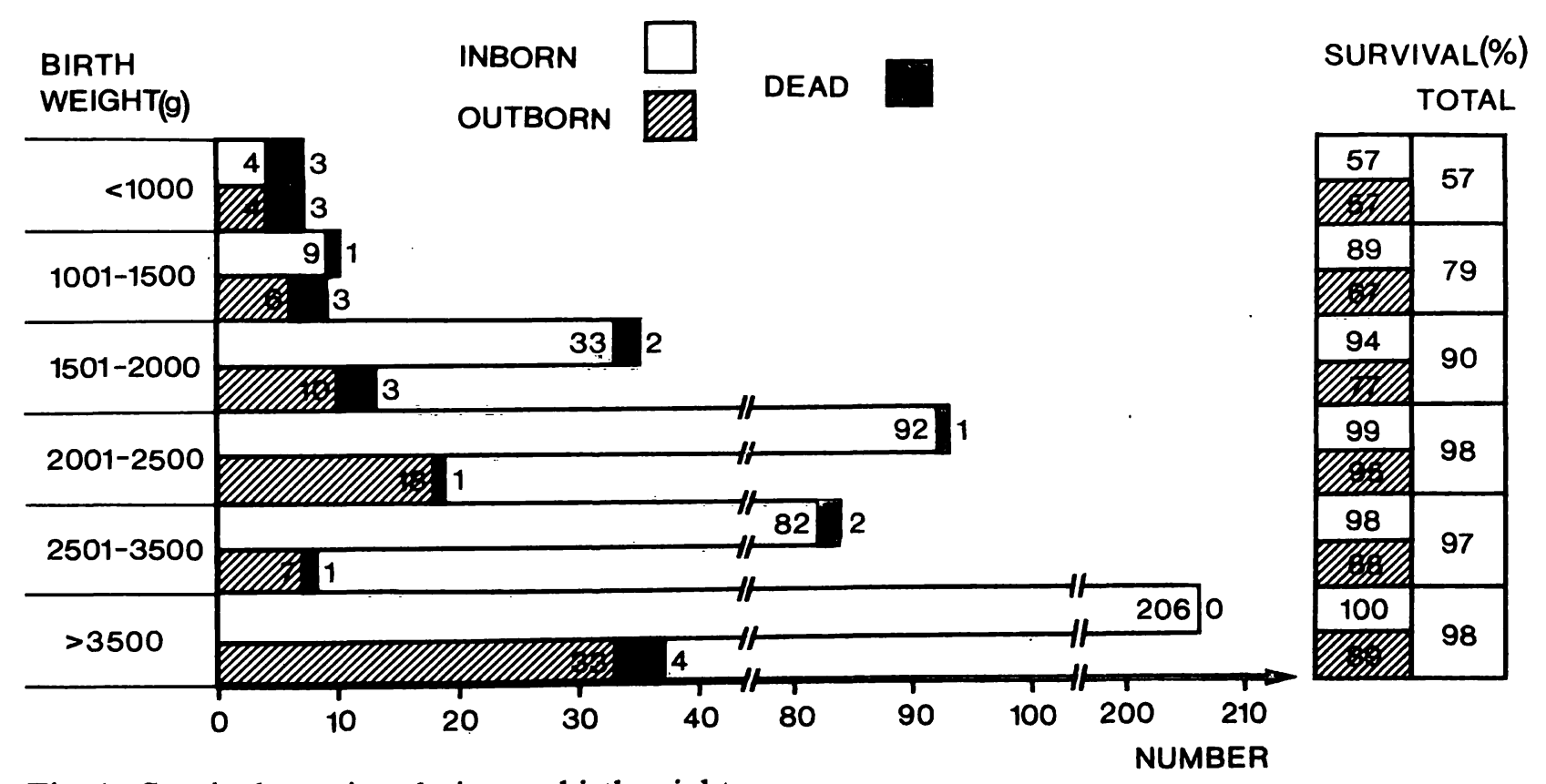

Fig. 1. Survival rate in relation to birthweight. 
$1001-1500 \mathrm{~g} 90 \%, 1501-2000 \mathrm{~g} 94 \%$ and $99 \%$ for infants above $2000 \mathrm{~g}$. The total survival rate for the 527 infants treated in the neonatal unit was $95 \%$.

The numbers of preterm infants ( $<37$ gestational weeks) were 105 for inborns and 45 for outborns. Small-for-gestational age (SGA) infants ( $<$ mean -2 SD of weight) were 48 and 9 respectively. In each group 4 infants were both preterm and SGA.

Respiratory difficulties was the major indication for transfer to the neonatal unit in 179 of 527 infants, i. e. $134(30.8 \%)$ inborns and $45(48.9 \%)$ outborns (Fig. 2). In 5 and 7 infants respectively the main cause of death was their respiratory illness. Pulmonary maladaptation (PMA) and mild respiratory distress (MRD) were the most common diagnoses (89 and 36 infants respectively). Idiopathic respiratory distress syndrome (IRDS) was diagnosed in 30 infants and pneunomia in 20 infants. Recurrent apnoea of immaturity was the only respiratory problem in 2 inborn infants but an additional problem in 3 inborn infants with IRDS and 4 outborn infants with IRDS and pneumonia.
Laboratory data ad admission: At admission to the neonatal unit the following were analyzed, i. e. blood hemoglobin, blood acid base, blood glucose and rectal temperature. Low hemoglobin and low $\mathrm{pH}$ occurred frequently in outborn transferrals. The incidence of low Bglucose and low rectal temperature $\left(<35.4{ }^{\circ} \mathrm{C}\right)$ was however, equal in both groups.

\subsection{Treatments}

The duration of treatment in the neonatal unit was in average 17 and 21 days for inborns and outborns, respectively. A major part of inborns stayed less than 5 days (Tab. III). A minority of infants stayed for weeks or months. These were the most immature requiring long-time adaptation and treatment.

The various treatments applied in the neonatal unit are shown in Fig. 3. Incubator care was used in 372 of 435 inborn and 83 of 92 outborn infants. Oxygen therapy was given to $171(41 \%)$ inborn and $64(68 \%)$ outborn infants. Oxygen therapy was given for more than 9 days in 39 inborn and 33 outborn infants, respectively.
INBORN

DEAD
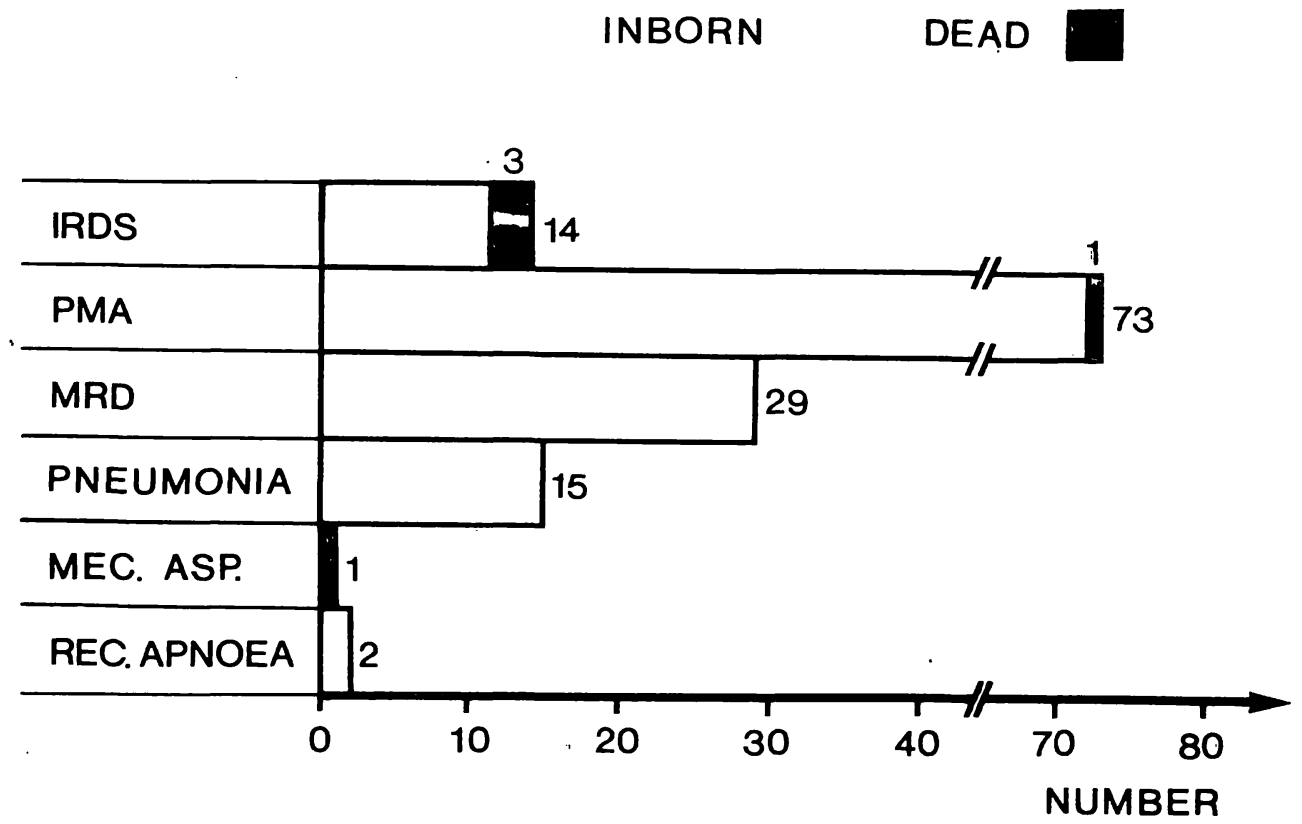

OUTBORN

TOTAL

Fig. 2. Respiratory disorders. IRDS = Idiopathic respiratory distress syndrome; PMA = Pulmonary maladaptation or transient tachypnoea; MRD = Mild respiratory distress. Mec asp = Meconium aspiration; Rec apnoea = Recurrent apnoea of prematurity. 
Tab. III. Duration of treatment in the neonatal unit.

\begin{tabular}{lllllll}
\hline Days & Inborn & \multicolumn{1}{c}{ Outborn } & Total & \\
& $\mathrm{N}=435$ & $\%$ & $\mathrm{~N}=92$ & $\%$ & $\mathrm{~N}=527$ & $\%$ \\
\hline $0-5$ & 199 & 45.7 & 21 & 22.8 & 220 & 41.8 \\
$6-15$ & 117 & 26.9 & 25 & 27.2 & 142 & 26.9 \\
$16-35$ & 76 & 17.5 & 26 & 28.3 & 102 & 19.4 \\
$36-60$ & 31 & 7.1 & 16 & 17.4 & 47 & 8.9 \\
$>61$ & 12 & 2.8 & 4 & 4.3 & 16 & 3.0 \\
\hline Average days & 17 & & 21 & & & \\
\hline
\end{tabular}

INBORN, TOTAL 435

OUTBORN, TOTAL 92

MEASURE

TOTAL

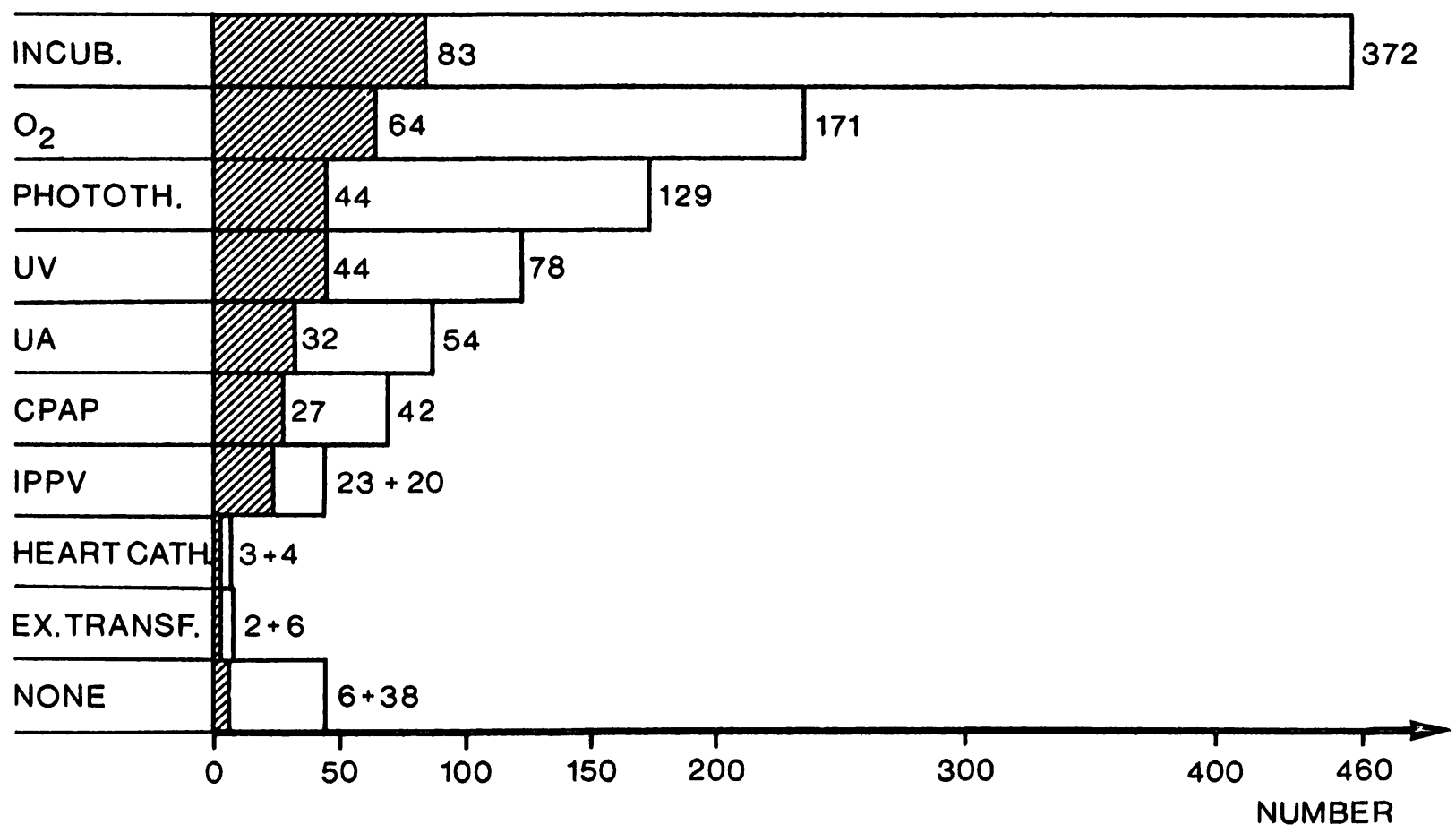

\begin{tabular}{|c|}
\hline 455 \\
\hline 235 \\
\hline 173 \\
\hline 122 \\
\hline 86 \\
\hline 69 \\
\hline 43 \\
\hline 7 \\
\hline 8 \\
\hline 44 \\
\hline
\end{tabular}

Fig. 3. Rate of therapeutic procedures in neonatal care management. UV $=$ Umbilical vein catheter; UA $=$ Umbilical artery catheter; CPAP $=$ Continuous positive airway pressure; IPPV $=$ Intermittent positive pressure ventilation; EX. TRANSF. = Exchange transfusion; HEARTH CATH. = Heart catheterization; PHOTOTH. = Phototherapy.

Phototherapy was administered to $129(34 \%)$ inborn and $44(45 \%)$ outborn infants. Phototherapy was given less than 5 days in the majority of these children. Only 10 inborn and 9 outborn infants were treated with phototherapy for more than 9 days. Exchange transfusions were required in only 8 infants (5 Rh-im- munization, $3 \mathrm{ABO}-$-immunization). Of the 69 continuous positive airway pressure-treated (CPAP) infants 41 (29 inborn and 12 outborn) were treated with CPAP only. CPAP failures were noted in 10 infants, while 18 infants were treated with CPAP as weaning off the intermittent positive pressure ventilation 
(IPPV). The duration of CPAP treatment was less than 4 days in 34 of the 41 infants. IPPV treatment was needed for more than 5 days in 31 of 43 infants.

\subsection{Complications}

In 60 infants umbilical catheters were inserted for more than 4 days. Except for one infant who had thrombosed umbilical veins at autopsy no other complications to umbilical catheterization during 1977 were recorded.

Septicaemia and/or meningitis complications during neonatal unit treatment were found in 8 inborn and 5 outborn infants, respectively.

The occurrence of lung complications in infants with respiratory disorders showed bronchopulmonary dysplasia (BPD) only in infants with IRDS $7 / 30(23 \%)$. Pneumothorax was mainly related to IRDS $10 / 30(33 \%)$ but also in $6 / 89$ (7\%) with pulmonary maladaptation (PMA).

\subsection{Outcome}

At follow-up examinations after $2-4$ years the rate of neurodevelopmental persistent handicap in inborn infants treated in the neonatal unit was $3 \%(n=13)$ and in outborns $10 \%(n=8)$. One child in each group with persistent handicap died within one year of age.
In this material the outcome of treatment in the neonatal unit showed an effectiveness of $84 \%$ and $98 \%$ in survival rate for outborns and inborns, respectively. The rate of survivors without permanent handicap was $90 \%$ and $97 \%$, respectively. In comparison the rate of survivors without permanent handicaps among inborn infants not treated in the neonatal unit in 1977 was $99 \%$. Thus the effectiveness regarding mortality and survival without handicap seems to be close to optimal.

I this retrospective study differentiated costs for intensive care patients per se were not available.

Data were obtained from the hospital administration regarding daily and total cost of treatment in the neonatal unit (527 infants) in comparison with the general pediatric clinic (3608 infants). The average total cost per child of in-hospital treatment was $25892 \mathrm{Sw}$. Cr. (3698 US \$) in the neonatal unit and $15300 \mathrm{Sw}$. Cr. (2185 US\$) for infants in the general pediatric clinic (Tab. IV). These amounts include both medical staff salaries $(85 \%$ of total costs), the cost of laboratory analyses as well as medical treatment and equipment and administrative expenses.

For comparison data from the regional rehabilitation centre authorities the estimated annual cost for a child (0-16 years) with persistent light or moderate to severe neurodevelopmental handicap is in the range of $150000-300000$ Sw. Cr. (21 500-43000 US \$). This comprises the total costs of rehabilitation

Tab. IV. Costs included in neonatal care 1977

Infants treated

Total in-hospital treatment (days)

Average treatment (days)

Average cost per child
527

9092

18

25892 Sw. Cr. (3698 US\$)

Annual costs of personnel staff supporting departments, e. g. X-ray, chemical laboratories etc. rentals, equipment and administration services

8818413 Sw. Cr. (1259773 US\$)

2096637 Sw. Cr. ( 299520 US \$)

3182711 Sw. Cr. ( 454673 US \$)

Annual expenditure for rehabilitation of a moderately to severely handicapped child

$150000-300000$ Sw. Cr. (21500-43 000 US \$) 
team of neuropediatric, orthopedic, logopedic, physiotherapy and social worker specialists.

\section{Discussion}

For the 10 referring clinics (outborn) in the southern part of Sweden with 14140 births this year, the perinatal mortality was $0.97 \%$ compared to $0.69 \%$ for the inborn infants. Thus the total regional perinatal mortality rate was $0.92 \%$. The variation between the referring clinics may partly be due to different indications for antenatal referral of mothers to the obstetric department in Lund. This also explains the higher low birthweight (LBW) rate in the inborn population. In general the principles of antenatal care is uniform in the southern part of Sweden as for Sweden as a whole. This may by itself lower the perinatal mortality $[4,12,13$, 28]. Whether improvements in perinatal mortality can be obtained by further increase of maternal transfers before delivery in Sweden cannot be decided from our present data. However, reports from neonatal centers in other countries indicate that such improvements can be expected when a total intramural perinatal care is provided [1, 22]. In agreement with a recent report [21] the post-perinatal mortality until 3 years of age was low also in the present material.

Sudden infant death syndrome (SIDS) occurred in 4 infants, i.e. one outborn infant treated in the neonatal unit and 3 inborn infants not treated in the neonatal unit. We found no increased rate of SIDS among the infants treated in our neonatal unit although high incidences have been reported from other countries [11].

Thus the longterm survival rate for infants with a birthweight below $1000 \mathrm{~g}$ was $57 \%$, between $1001-1500 \mathrm{~g} 90 \%$ and above $1500 \mathrm{~g} 94-100 \%$. Similar results have been presented in other studies [26]. However, it has been emphasized that in order to achieve and preserve such results neonatal units are required despite their high costs $[2,24]$.

In outborns most referral diagnoses were respiratory disorders complicating prematurity.
The right use of mechanical ventilation in a tiny preterm baby of less than $1000 \mathrm{~g}$ is a highly specialist matter. The danger of "half-measures", i. e. success in saving the baby's life but failure to save him from subsequent handicaps must be avoided. This implies that training in specialized skills for doctors and nurses for optimal application of the many specific maneuvres must be included in a neonatal care programme $[19,24]$. The need for highly specialized care in our region 1977 was $0.33 \%$ (outborn) and 1.04\% (inborn) reflecting the higher antenatal referral to the regional center.

In this study transportation related problems were mainly low blood hemoglobin and $\mathrm{pH}$ at arrival in the neonatal unit of outborn infants, and low body temperature in some inborns as well. This points to the essentials of stabilization and correction before transportation, escpecially in the smallest infants. If possible transportation in utero is to be preferred [7].

In the present study many inborn and some outborn infants from hospitals without a pediatric ward stayed in the noenatal unit for postnatal minor problems of adaptation for just a few days. Only $12 \%$ of the neonatal unit treated population needed treatment for more than 35 days and only $3 \%$ for more than 61 days. The latter were mainly very immature preterms and some infants with severe bronchopulmonary dysplasia [16]. The duration of treatment is not only related to severity of the neonatal disease but also to other factors, e.g. local geographical circumstances and structure of the regional perinatal organisation $[18,20$, 22] as well as provision of transitional neonatal care [17] and family-centered maternity and newborn units [14]. Neonatal disease or adaptive disorders in the perinatal period can on one hand endanger the life of the newborn baby and on the other hand influence the sensitive parent-infant relationship or cause lifelong handicaps [10].

As pointed out by SincLaIR [24], even if we accept the position that neonatal care is effective there remains the question of efficiency evaluation (economic evaluation). Economic analy- 
sis of the average per patient hospital costs showed a less than expected difference between the general pediatric clinic (2185 US \$) and the neonatal unit populations (3698 US \$).

Economic expenditures for the family may as well have implications on the sensitive parentinfant bonding and careing relationship necessary to cope with the care after discharge [25].

In our opinion studies also must integrate the cost of handicapped children for family and society. This has been calculated in terms of saved lives and additional cerebral palsied children by HAGBERG et al. [8]. They have estimated that one of every 40 saved lives in Sweden acquired a mild or moderate cerebral palsy syndrome, i. e. a net gain of lives saved without cerebral palsy during the 1970's. In the present study the concept of regionalization is supported by the perinatal mortality figures which were $0.69 \%$ in inborn infants and in average $0.97 \%$ in the other hospitals in the region (Tab. I). The net gain of perinatal survival could possibly be estimated to 30 lives if all risk pregnancies had been regionalized. However, the net gain of lives saved without cerebral palsy, being $98 \%$ for the inborn total population, could not be calculated for the outborn total population owing to insufficient data available in outborn children not treated in the regional neonatal center.

Vast differences between countries may have several reasons as observed by WYNN and WANN [29]. In order to obtain comparable data on the total impact of neonatal care programmes the specialized peri- and neonatal units should be regionalized. Issues like transportation and regionalization are essential for evaluation of the apparently expensive neonatal care. This has been shown to be important for the great improvements in the care of very low birthweight infants (VLBW) $(<1500 \mathrm{~g})$ and certain other groups of very ill newborn infants $[2,7$, $15,24,29]$. To justify the need of such centres with appropriate investments from the viewpoint of society, more detailed data can be collected in collaboration between administrators and the medical profession $[2,6]$. Future prospective analysis may enable more correct comparisons regarding effectiveness of neonatal care and cost-efficiency in the prevention of handicap.

\section{Summary}

A one-year population of 527 newborn infants treated in a Swedish neonatal unit was studied with regard to the effectiveness of the neonatal care in rate of normal survival and rate of handicaps at 3 years of age.

The effectiveness could be accurately calculated in terms of survival rate being $84 \%$ and $98 \%$ of outborns and inborns respectively, and in terms of survivors without neurodevelopmental handicaps at 3 years of age being $90 \%$ and $97 \%$, respectively.

From available data on the cost of the neonatal care it could be estimated that the average annual costs for rehabilitation care for a light or moderately to a severely

handicapped child were 5.8 to 11.2 times higher than in average per patient in-hospital costs during neonatal treatment. It is evident that skills in specialized neonatal care are indispensable for optimal outcome for very small low birthweight infants below $1500 \mathrm{~g}$ or born before $30(-32)$ weeks of gestation.

However, in order to evaluate the return on expenditure for prevention of handicaps from the viewpoint of society adequate data on effectiveness of treatment as well as economic cost-efficiency are necessary for local and regional organization of neonatal care units.

Keywords: Cost-efficiency, neonatal care, perinatal mortality, regionalization.

\section{Zusammenfassung}

Untersuchungen an Kindern nach Aufenthalt auf einer schwedischen Neugeborenenstation

Untersucht wurde eine Gruppe von 527 Neugeborenen, die innerhalb eines Jahres auf einer schwedischen Neuge- borenenstation betreut wurde. Um die Effizienz der Neugeborenenüberwachung zu überprüfen, untersuchten wir die Kinder im Alter von 3 Jahren und bestimmten die Überlebensrate und die Häufigkeit von Behinderungen. 
Als Ausdruck der Effizienz konnte die Überlebensrate genau berechnet werden. Sie betrug bei den außerhalb erfolgten Geburten $84 \%$ und bei den Geburten in der eigenen Klinik $98 \%$. Der Anteil von überlebenden Kindern ohne neurologische Entwicklungsverzögerungen ließ sich ebenfalls exakt feststellen und betrug im Alter von 3 Jahren bei den außerhalb erfolgten Geburten $90 \%$ und bei den Geburten in der eigenen Klinik $97 \%$.

Die zur Verfügung stehenden Daten sagen aus, daß die durchschnittlicheen, jährlichen Kosten für die Rehabilitation bei einer leichten bzw. mittelgradigen bis zu einer hochgradigen Behinderung 5.8 bis 12.2-mal höher sind als die durchschnittlichen Kosten pro Patient auf einer
Neugeborenenstation. Es ist klar, daß spezialisierte Neugeborenenstationen Fachkräfte brauchen, um Kinder mit niedrigem Geburtsgewicht $(<1500 \mathrm{~g})$ und Frühgeborene $(<30 .-32$. Schwangerschaftswoche) optimal zu betreuen.

Um aber Untersuchungen über die Wirksamkeit von Aufwendungen für die Prävention von Behinderungen unter sozio-ökonomischen Gesichtspunkten durchführen zu können, müssen adäquate Daten über die Effizienz der Behandlung wie auch Kosten-Nutzen-Analysen vorliegen. Sie sind für die lokale und regionale Organisation von Neugeborenenstationen notwendig.

Schlüsselwörter: Kosten-Nutzen-Analyse, perinatale Mortalität, regionale Planung, Überwachung von Neugeborenen.

\section{Résumé}

Bilan d'un an de soins néo-nataux en suéde

Un groupe annuel de 527 nouveau-nés traités dans une unité néo-natale suédoise a été étudié sur le plan de l'efficacité des soins néo-nataux en pourcentage de survivants normaux et en pourcentage de handicaps à l'âge de 3 ans.

L'efficacité peut être calculée de façon appropriée, en terme de pourcentage de survivants, ces pourcentages sont de $84 \%$ pour les enfants nés à l'extérieur et de $98 \%$ pour les enfants nés dans l'unité, et en terme de survivants sans handicaps psychomoteurs à l'âge de 3 ans, avec des taux de $90 \%$ et de $97 \%$ respectivement.

En se fondant sur les données disponibles concernant le coût de soins néo-nataux, on peut estimer que le coût annuel moyen de rééducation d'un enfant atteint d'un handicap léger et moyen ou sévère est de 5,8 à 11,2 fois plus élevé que le coût moyen, par patient hospitalisé, du traitement néo-natal. Il est évident que la compétence des unités de soins néo-nataux spécialisés est indispensable pour assurer un avenir optimal aux enfants de très faible poids de naissance, inférieur à $1500 \mathrm{~g}$ ou nés avant $30(<32)$ semaines de gestation.

Cependant, afin d'évaluer le bénéfice en matière de dépenses pour la prévention des handicaps du point de vue de la société, des données adéquates concernant l'efficacité du traitement de même que le bénéfice en matière de coût économique sont nécessaires pour l'organisation locale et régionale d'unités de soins néo-nataux.

Mots-clés: Efficacité-coût, mortalité périnatale, régionalisation, soins néo-nataux.

Acknowledgements: This study was supported by grants from the First of Mayflower Research Foundation, the Sven Jerring Research Foundation, Margaretahemmet Research Foundation, Allmänna Barnbördshuset Research Foundation and the Swedish Medical Research Council grant No. B82-19X-04732-07.

\section{Bibliography}

[1] Blake, A. M., M. J. Pollitzer, E. D. R. Reynolds: Referral of mothers and infants for intensive care. Br. Med. J. 2 (1979) 414

[2] Boyle, M. H., G. W. Torrance, J. C. Sinclair, S. P. HORNWOOD: Economic evaluation of neonatal intensive care of very low birthweight infants. $\mathrm{N}$. Engl. J. Med. 308 (1983) 1330

[3] Campell, A. G. M.: Which infants should not receive intensive care? Arch. Dis. Child. 57 (1982) 569

[4] Davies, P. A.: Perinatal mortality. Arch. Dis. Child. $55(1980) 833$
[5] Delvin, E. E., F. H. Glorieux, B. L. Salle, L. DAVID, J. P. VARENNE: Control of vitamin D metabolism in preterm infants: feto-maternal relationships. Arch. Dis. Child. 69 (1982) 143

[6] DRUmmond, M. F.: Principles of economic appraisal in health care. Oxford Univ. Press 1980, pp 2-5

[7] GreEN, W. T.: Organization of neonatal transport services in support of regional referral center. Symposium on Neonatal Intensive Care. Clin. Perinatol. 7 (1980) 187

[8] Hagberg, B., G. Hagberg, I. Olow: Gains and hazards of intensive neonatal care: an analysis from 
Swedish cerebral palsy epidemiology. Dev. Med. Child. Neurol. 24 (1982) 13

[9] HJalmarsson, O.: Epidemiology and classification of acute neonatal respiratory disorders. Acta Paediatr. Scand. 70 (1981) 773

[10] JeffCoate, J. A., M. E. Humphrey, J. K. Lloyd: Disturbance in parent-child relationship following preterm delivery. Dev. Med. Child. 21 (1979) 344

[11] Kelly, D. H., D. C. Shannon: SIDS and NSIDS. A review of the literature. In: Symposium on the newborn. Pediatr. Clin. North Am. 29 (1982) 1241

[12] Kiely, J. L., N. Paneth, Z. Stein, M. Susser: Cerebral palsy and newborn care. III. Mortality and neurological impairment in low birthweight infants. Dev. Med. Child. Neurol. 23 (1981) 650

[13] Kiely, J. L., N. Paneth, Z. Stein, M. Susser: Cerebral palsy and newborn care. I. Secular trends in cerebral palsy. Dev. Med. Child. Neurol. 23 (1981) 533

[14] KLAus, M., J. KenNell: Interventions in the premature nursery: Impact on development. In: Symposium on the Newborn. Pediatr. Clin. North Am. 29 (1982) 1263

[15]. Lindroth, M., N. W. SVEnNingsen, H. Ahlström, B. JONSON: Evaluation of mechanical ventilation in new.born infants. I. Techniques and survival rates. Acta Paediatr. Scand. 69 (1980) 143

[16] Lindroth, M., B. Jonson, N. W. Svenningsen, W. MORTENSSON: Pulmonary mechanics, chest X-ray and lung disease after mechanical ventilation in low birthweight infants. Acta Paediatr. Scand. 69 (1980) 761

[17] ORMER, R. L. E., J. BOXALL: The changing pattern of parental involvement in the special care baby unit in Exeter. In: Separation and special care baby units. Clin. Dev. Med. 68 (1978) 64

[18] Paneth, N., J. L. KIely, S. Wallenstein, M. Marcus, J. PAKTER, M. SusSer: Newborn intensive care and neonatal mortality in low birthweight infants. N. Engl. J. Med. 307 (1982) 149

[19] Roberton, N. R. C.: Advances in respiratory distress syndrome. Br. Med. J. 284 (1982) 917
[20] Scotr, R. J.: Regionalisation: A time for new solutions. Symposium on the Newborn. Pediatr. Clin. North Am. 24 (1977) 651

[21] Sells, C. J., T. E. Neff, F. C. Bennet, N. M. ROBINSON: Mortality in infants discharged from a neonatal intensive care unit. Am. J. Dis. Child. 137 (1983) 44

[22] Shennan, A. T., J. E. Millian: Annual report 1979 from the Perinatal Unit, Women's College Hospital, Toronto

[23] SILVERMAN, W. A.: Retinopathy of prematurity: oxygen dogma challenged. Arch. Dis. Child. 57 (1982) 731

[24] Sinclatr, J. C., G. W. Torrance, M. H. Boyle, S. P. HORWOOD, S. SAIGAL, D. L. SACHETT: Evaluation of neonatal-intensive-care programs. N. Engl. J. Med. 305 (1981) 489

[25] SmITH, M. A., I. D. BAum: Costs of visiting babies in special care baby units. Arch. Dis. Child. 58 (1983) 56

[26] Stanley, F. J., M. S. T. HobBs: Neonatal mortality and cerebral palsy: the impact of neonatal intensive care. Aust. Pediatr. J. 16 (1980) 35

[27] Steiner, E. S., E. M. Saunders, E. C. K. Philips, C. R. MADDOCK: Very low birthweight children at school age: comparison of neonatal management methods. Br. Med. J. 281 (1980) 1237

[28] STEWART, A. L., E. O. R. ReYNolds, A. P. LIPSCOMB: Outcome for infants of very low birthweight: survey of world literature. Lancet I (1981) 1038

[29] WynN, M., A. WYNN: Prevention of handicap of perinatal origin. An introduction to French policy and legislation. Foundation for education and research in child-bearing. London 1976

Received February 22, 1984. Revised May 11, 1984, Accepted May 18, 1984.

Peter Holmqvist, M. D. Dept. of Pediatrics University Hospital 22185 Lund/Sweden 